\title{
Complete esophageal obstruction after endoscopic variceal band ligation
}

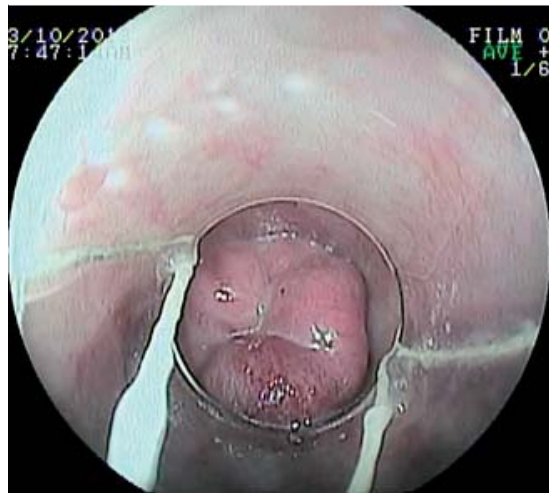

Fig. 1 Placement of the band during endoscopic variceal ligation. After the band had been placed, we observed that the banded varix almost occluded the esophageal lumen.

Endoscopic variceal band ligation (EVL) is the endoscopic therapy of choice for esophageal varices. We present a very rare complication of EVL: complete esophageal obstruction [1].

A 64-year-old woman with cirrhosis was admitted for her fourth EVL. During the procedure, esophageal mucosal scarring from previous ligation, mild stenosis of the lower third of the esophagus, and a single large varix were identified. The large varix was ligated with only one band (Cook Medical, Bloomington, Indiana, USA). The banded varix almost occluded the esophageal lumen ( $\bullet$ Fig. 1 , - Video 1).

The patient was sent home asymptomatic. Dysphagia, vomiting, and chest pain developed, and she returned to our emergency department appearing ill. The physical examination findings were normal. A Gastrografin swallow showed esophageal dilatation with complete obstruction at the distal esophagus ( Fig.2). During upper gastrointestinal endoscopy, black mucosa and a complete esophageal obstruction were found at the site of the previous banding ( $\bullet$ Fig. 3, Video 2 ). The patient was given nothing by mouth for 7 days, after which she was able to tolerate a liquid diet. By day 11, she could tolerate a full diet. At 4 months after EVL, she is asymptomatic.

Complete esophageal obstruction is a very rare event. To our knowledge, only three other cases have been reported in the lit-

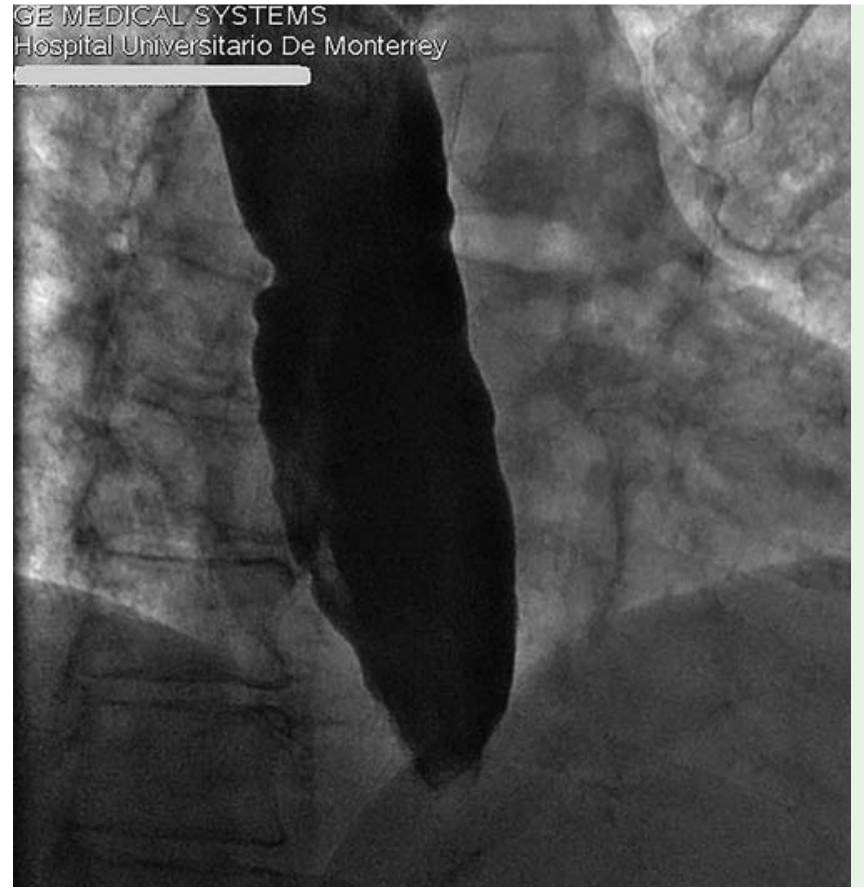

Fig. 2 Later, Gastrografin swallow shows esophageal dilatation with complete obstruction at the distal esophagus.

erature. Verma et al. [2] and Nikoloff et al. [3] separately reported patients with complete esophageal obstruction after a second EVL procedure. Both patients completely recovered with only supportive therapy. Chahal et al. [4] reported a similar patient; however, they tried unsuccessfully to reopen the esophagus with a biopsy forceps, and esophageal dissection occurred. The patient completely recovered without further intervention.

Several factors and mechanisms can be involved in the development of an esophageal obstruction, such as a large size of the varix, the excessive use of suction, mucosal scarring due to previous ligation procedures, and esophageal stenosis. It is suggested that this complication may be prevented with a correct banding technique and careful suctioning of the esophageal varix. Most of the time, only supportive therapy is needed.

\section{Video 1}

Placement of the band during endoscopic variceal ligation. The banded varix almost occludes the esophageal lumen.

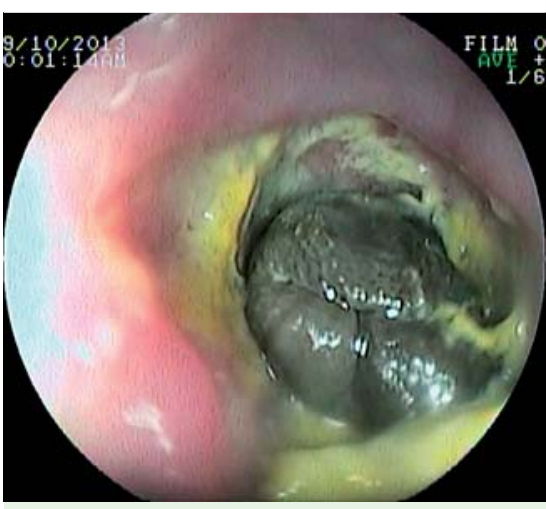

Fig. 3 Subsequent endoscopy shows black mucosa and complete esophageal obstruction at the site of the previously banded area.

Endoscopy_UCTN_Code_CPL_1AH_2AJ

Competing interests: None

\section{Video 2}

Subsequent endoscopy shows black mucosa and complete esophageal obstruction at the site of the previously banded area. 
Reyna L. Elizondo-Rivera, José A. González-González, Diego Garcia-Compean, Hector J. Maldonado-Garza

Gastroenterology Department, Hospital Universitario Dr. José Eleuterio González, Monterrey, Nuevo León, Mexico

\section{References}

1 Garcia-Tsao G, Sanyal AJ, Grace ND et al. Prevention and management of gastroesophageal varices and variceal hemorrhage in cirrhosis [published correction appears in Am J Gastroenterol 2007; 102: 2868]. Am J Gastroenterol 2007; 102: 2086-2102

2 Verma $D$, Pham C, Madan A. Complete esophageal obstruction: an unusual cause of esophageal band ligation. Endoscopy 2009; 41 (Suppl. 02): E200-E201

3 Nikoloff MA, Riley TR, Schreibman IR. Complete esophageal obstruction following endoscopic variceal ligation. Gastroenterol Hepatol 2011; 7: 557-559

4 Chahal H, Ahmed A, Sexton C et al. Complete esophageal obstruction following endoscopic variceal band ligation. J Community Hosp Intern Med Perspect 2013: 3. doi: 10.3402

\section{Bibliography}

Dol http://dx.doi.org/

10.1055/s-0034-1377528

Endoscopy 2014; 46: E457-E458

(c) Georg Thieme Verlag KG

Stuttgart · New York

ISSN 0013-726X

\section{Corresponding author}

José A. González-González, MD

Gastroenterology Department

Hospital Universitario Dr. José Eleuterio González Av. Francisco I. Madero y Gonzalitos sin número Mitras Centro

64460 Monterrey, Nuevo León

Mexico

jalbertogastro@gmail.com 